\title{
THE WHITE PAPER
}

SIR,-Having followed the controversy which has been raging for twelve months concerning the pros and cons of a State Medical Service, I thought that perhaps the opinion of a rank and file G.P. might be of interest.

I think the real root of the reluctance of the medical profession to enter the State Service is financial. No one believes that State Medicine will pay the remuneration that the present private and panel pays.

In the appendix to the White Paper a sum of $£ 30,000,000$ is mentioned as possibly covering the doctors' and chemists' services under the proposed scheme as against ro. 8 million pounds for the combined doctors and chemists in $193^{8}$ for 18 million people. On these figures, it would seem that the Government's idea of the new capitation fee is about one-third greater than the present one. These contrast with the figures from my own practice (an ordinary industrial one) showing that private is three times more remunerative than panel.

Again, a doctor in private practice gets his income roughly in three ways:-

(I) A portion for salary for acting as his own assistant.

(2) A portion for managing his practice.

(3) A portion for return on his capital invested in his own practice.

Items 2 and 3 representing I should think five-sixths of one's income.

Obviously you can hardly expect the Government's scale of remuneration to offer anything for services 2 and 3 , since these services will largely be performed for us.

If remuneration under the State Scheme is to compare with present G.P. earnings, the whole scale of medical salaries-for M.O.H.s and Medical Superintendents-would have to be altered. These salaried workers only tolerate the earnings of G.P.s at present because they recognise the right for return on capital.

Since the majority of G.P.s operate their own practices, the introduction of any scale of salaries the Government would be likely to pay would obviously drastically lower the standard of living of the bulk of practising G.P.s.

Since no one cares to oppose Beveridge proposals openly, the G.P.s are in an impasse; they see a serious likelihood of their standard of living being drastically lowered whether a salaried State service or a universal panel is adopted, since it is stated in the White Paper that the capitation fee would be based on the salaries paid at the health centres. I should think that similar considerations must affect the consultant class, but I have no first-hand knowledge of this. to it.

I am afraid that $I$ have no ready-made solution to this impasse, but I feel that attention should be drawn

OLdHam,

\section{B. DUNKERLEY}

May 16, 1944.

\section{POST-GRADUATE EDUCATION}

Sir,-Dr. Trevor H. Howell has written* suggesting that greater efforts should be made in all teaching centres to popularise and co-ordinate post-graduate teaching. In his article he quite rightly points to the relative simplicity of providing courses for candidates for higher examinations and the relatively difficult task of providing the right sort of courses for the general practitioner. Whilst I agree entirely with the suggestions he makes, I think he has missed the most important necessary step, namely the opening up of hospital wards and out-patients to local G.P.s.

Post-graduate education as we in the teaching schools enjoy it amongst ourselves, consists in the perpetual interplay of thoughts and ideas between the individual members of the staffs and between staffs and students. Starting from such a point, a refresher course or a visit to a foreign clinic becomes an enlivening variation of the endless debate in which we live. ' Only by admitting the G.P. to this "University" of post-graduate medicine can we hope to achieve and maintain a raised standard of medical post-graduate education.

I firmly believe that the organisation of the right sort of hospital system is the most important single problem facing the profession-and indeed, from the medical point of view, the country as a whole-at this time. All biggish hospitals in an area should be directly associated with the hospitals of the teaching school of that area. Between them there should be a constant interchange of staff for purposes of perpetual reeducation such as I have described. Around the bigger hospitals, smaller ones should be grouped, looking towards their bigger neighbours for encouragement and advice in a similar manner. At the extreme periphery Cottage Hospitals might revert to their former function and become again the places wherein G.P.s may themselves treat their more seriously ill patients. But throughout the whole of this informed system of hospitals the G.P. should be expected to come and go with his own patients and to contribute to discussion, and so to teach and learn at the same time.

This cannot come overnight, nor will it ever come without effort. It demands, first, the right sort of hospital system; secondly the right sort of hospital area; thirdly an effective link between hospital and general practice; fourthly an increase in personnel at all levels to afford leisure for those most profitable and desirable habits of reflection and discussion which form the true essence of University life, and away from which even the most fortunate (in this respect) have been swept by the tide of events.

LIVERPOOL $\mathbf{I}$.

Charles Wells

$$
\text { * P.-G.M.J., May 1944. }
$$

